\title{
ANALISIS RANCANGAN TEKNOLOGI MOBILE APPLICATION PADA E-BOOKING RUANGAN UNTUK KEGIATAN UKM
}

\author{
Agus Purwanto ${ }^{1)}$, Anggun Nugroho ${ }^{2)}$ \\ Program Studi Sistem Komputer, STMIK STIKOM Bali, Denpasar ${ }^{1) 2)}$ \\ purwanto@stikom-bali.ac.id ${ }^{1)}$, anggun@stikom-bali.ac.id ${ }^{2)}$
}

\begin{abstract}
Students Activity Unit or abbreviated UKM in STIKOM Bali is a student organization managed by students under the coordination of Assistant III Chairman of Student Affairs. Activities undertaken by SMEs is a non-academic activities that are useful to mediate interests and talents of students in the field of non-academic. Currently more than 25 SMEs in STIKOM Bali are coordinated by PK III. Activities undertaken are usually done on campus and off campus by utilizing the space and fascities available on campus itself. To use the existing room and facilities SME managers must place orders to the relevant sections so that their use can be controlled. Room reservation system is done so far still using the manual way that SME managers come directly to units of Facilities and Infrastructure (SARPRAS) to reserve the space to be used. Therefore, it is necessary to apply for room rental booking with Android based for SME managers easier to book the room. but also to facilitate SME managers to obtain information on the available space at the desired time. With the application of this application later lending space can be resolved by using information and communication technology (ICT), without having to come directly to the unit Sarpras so that the relevant part easier to manage and monitor the use of the room by SMEs in STIKOM Bali. This mobile app is built using android operating system using Android Studio. This application allows customers to register and make room reservations in accordance with the time required and the type of room in accordance with the capacity of the room. This application also uses My SQL for database storage as well as using the application adobe dreamweaver to create a web server to be easily dikelaola by the administrator in this Sarpras unit.
\end{abstract}

Keywords : ukm, booking, booking system, android

\begin{abstract}
ABSTRAK
Unit Kegiatan Mahaiswa atau disingkat UKM di STIKOM Bali merupakan organisasi mahasiswa yang dikelola oleh mahasiswa dibawah koordinasi Pembantu Ketua III Bidang Kemahasiswaan. Kegiatan yang dilakukan oleh UKM ini adalah kegiatan non akademis yang berguna untuk memediasi minat dan bakat para mahasiswa di bidang non akademis. Saat ini lebih dari 25 UKM di STIKOM Bali yang dikoordinasi oleh PK III. Kegiatan-kegiatan yang dilakukan biasanya dilakukan di kampus dan di luar kampus dengan memanfaatkan ruangn dan fasislitas yang tersedia di kampus itu sendiri. Untuk menggunakan ruangan dan fasilitas yang ada para pengurus UKM harus melakukan pemesanan ke bagian terkait agar penggunaannya dapat terkontrol. Sistem pemesanan ruangan yang dilakukan selama ini masih menggunakan cara manual yaitu pengurus UKM datang langsung ke unit Sarana dan Prasarana (SARPRAS) untuk memesan ruang yang akan digunakan. Oleh karena itu, diperlukan aplikasi pemesanan peminjaman ruangan dengan berbasis Android agar pengurus UKM lebih mudah untuk memesan ruangan. selain itu juga untuk memudahkan pengurus UKM memperoleh informasi ruangan yang tersedia pada waktu yang diinginkan. Aplikasi mobile ini dibangun dengan menggunakan sistem operasi android dengan menggunakan Android Studio. Aplikasi ini memungkinkan pelanggan melakukan registrasi dan melakukan pemesanan ruangan sesuai dengan waktu yang dibutuhkan serta jenis ruangan sesuai dengan kapasitas ruangan. Aplikasi ini juga menggunakan $M y S Q L$ untuk penyimpanan basis data serta menggunakan aplikasi adobe dreamweaver untuk membuat web server agar dapat mudah dikelaola oleh administrator dalam hal ini unit Sarpras.
\end{abstract}

Kata kunci : ukm,pemesanan, sistem booking, android 


\section{PENDAHULUAN}

Unit Kegiatan Mahasiswa atau dising-kat UKM di STIKOM Bali merupakan orga-nisasi mahasiswa yang dikelola oleh maha-siswa dibawah koordinasi Pembantu Ketua III Bidang Kemahasiswaan. Kegiatan yang dilakukan oleh UKM ini adalah kegiatan non akademis yang berguna untuk memediasi minat dan bakat para mahasiswa di bidang non akademis. Saat ini lebih dari 25 UKM di STIKOM Bali yang dikoordinasi oleh Pembantu Ketua bidang kemahasiswaan (PK III).

Kegiatan-kegiatan yang dilakukan bia-sanya dilakukan di kampus dan di luar kampus dengan memanfaatkan ruangn dan fasilitas yang tersedia di kampus itu sendiri. Untuk menggunakan ruangan dan fasilitas yang ada para pengurus UKM harus melakukan order ke bagian terkait agar penggunaannya dapat terkontrol. Sistem pemesanan ruangan yang dilakukan selama ini masih menggunakan cara manual yaitu pengurus UKM datang langsung ke unit Sarana dan Prasarana (SARPRAS) untuk memesan ruang yang akan digunakan. Oleh karena itu, diperlukan aplikasi pemesanan peminjaman ruangan dengan berbasis Android agar pengurus UKM lebih mudah untuk memesan ruangan. selain itu juga untuk memudahkan pengurus UKM memperoleh informasi ruangan yang tersedia pada waktun yang diinginkan.

Dengan adanya sebauh sistem ini nantinya pemesanan peminjaman ruangan bisa teratasi dengan menggunakan teknologi infor-masi dan komunikasi (TIK), tanpa harus datang langsung ke unit Sarpras sehingga bagian terkait lebih mudah dalam mengelola dan me-monitor penggunaan ruangan oleh UKM yang ada di STIKOM Bali. Aplikasi mobile ini di-bangun dengan menggunakan sistem operasi android dengan menggunakan Android Studio. Aplikasi ini memungkinkan pelanggan melaku-kan registrasi dan melakukan pemesanan ru-angan sesuai dengan waktu yang dibutuhkan serta jenis ruangan sesuai dengan kapasitas ruangan. Aplikasi ini juga menggunakan My SQL untuk penyimpanan basis data serta menggunakan aplikasi adobe dreamweaver untuk membuat web server agar dapat mudah dikelola oleh administrator dalam hal ini unit Sarpras.

\section{TINJAUAN PUSTAKA}

\section{STATE OF THE ART}

Penelitian mengenai "Implementasi Sistem Informasi Pemesanan Pakaian Distro dengan Aplikasi Android", yang dipublikasi-kan oleh Yusuf Agung Pramono dari Uni-versitas Muhammadiyah Surakarta. Pada pene-litian ini dihasilkan sebuah implementasi sis-tem pemesanan pakaian pada Distro Denim di kota Yogyakarta dengan menggunakan sistem operasi Ginger dan trknologi pengembang eclipse dan MySQL sebagai databasenya.

Penelitian dengan judul "Aplikasi Penjualan Online Berbasis Android (Studi kasus : Toko Hoax Merch)", yang dipublikasikan pada jurnal Computech dan Bisnis oleh Marjito dan Gina Tesaria dari STMIK Mardira Indonesia. Pada penelitian ini dihasilkan sebuah aplikasi bebrbasis android untuk penjualan pada toko hoaxmerch, dimana sistem ini dapat menjadi m-commerce bagi pengusaha dalam penetrasi yang lebih luas dengan memanfaatkan teknologi informasi

\section{ANDROID}

Android adalah sebuah kumpulan perangkat lunak untuk perangkat mobile yang mencakup sistem operasi, middleware dan aplikasi utama mobile [1]. Android memiliki empat karakteristik sebagai berikut :

- Terbuka. Android dibangun untuk benarbenar terbuka sehingga sebuah aplikasi dapat memanggil salah satu fungsi inti ponsel seperti membuat panggilan, mengirim pesan teks, menggunakan kamera, dan lainlain. Android menggunakan sebuah mesin virtual yang dirancang khusus untuk mengoptimalkan sumber daya memori dan perangkat keras yang terdapat di dalam perangkat. Android merupakan open source, dapat secara bebas dipe-luas untuk memasukkan teknologi ba-ru yang lebih maju pada saat teknologi tersebut muncul. Platform ini akan terus berkembang untuk membangun aplikasi mobile yang inovatif.

- Semua aplikasi dibuat sama. Android tidak memberikan perbedaan terhadap aplikasi utama dari telepon dan aplikasi pihak ketiga (third-party appli-cation). Semua aplikasi dapat dibangun untuk memiliki akses yang sama terhadap kemampuan sebuah telepon dalam menyediakan layanan dan aplikasi yang luas terhadap para peng-guna.

- Memecahkan hambatan pada aplikasi. Android memecah hambatan untuk membangun aplikasi yang baru dan inovatif. Misalnya, pengembang dapat menggabungkan informasi yang diperoleh dari website dengan data pada ponsel seseorang seperti kontak pengguna, kalender, atau lokasi geografis. 
- Pengembangan aplikasi yang cepat dan mudah. Android menyediakan akses yang sangat luas kepada pengguna untuk menggunakan library yang diperlukan dan tools yang dapat diguna-kan untuk membangun aplikasi yang semakin baik. Android memiliki sekumpulan tools yang dapat digunakan sehingga membantu para pengembang dalam meningkatkan produktivitas pada saat membangun aplikasi yang dibuat Google Inc. sepenuhnya membangun Android dan menjadikannya bersifat terbuka (open source) sehingga para pengembang dapat menggunakan Android tanpa mengeluarkan biaya untuk ijin dari Google dan dapat membangun Android tanpa adanya batasan-batasan. Android Software Development Kit (SDK) menyediakan alat dan Application Programming Interface (API) yang diperlukan untuk mulai mengembangkan aplikasi pada platform Android menggunakan bahasa pemrograman Java [2].

\section{PEMESANAN}

Pemesanan adalah suatu aktivitas yang dilakukan oleh konsumen sebelum membeli. Untuk mewujudkan kepuasan konsumen maka perusahaan harus mempunyai sebuah sistem pemesanan yang baik.[3] mendefinisikan pemesanan adalah "proses, perbuatan, cara memesan (tempat,barang,dsb) kepada orang lain".

Pemesanan dalam arti umum adalah perjanjian pemesanan tempat antara 2 (dua) pihak atau lebih, perjanjian pemesanan tempat tersebut dapat berupa perjanjian atas pemesanan suatu ruangan, kamar, tempat duduk dan lainnya, pada waktu tertentu dan disertai dengan produk jasanya. Produk jasa yang dimaksud adalah jasa yang ditawarkan pada perjanjian pemesanan tempat tersebut, seperti pada perusahaan penerbangan atau perusahaan pelayaran adalah perpindahan manusia atau benda dari satu titik (kota) ke titik (kota) lainnya.

Dalam melakukan pemesanan hal yang harus diperhatikan adalah sebagai berikut:

- Product (produk), adalah segala sesuatu yang dapat ditawarkan ke pasar untuk diperhatikan, diperoleh dan digunakan atau dikonsumsi untuk dapat memenuhi kebutuhan dan keinginan meliputi barang fisik, jasa, orang, tempat, organisasi, gagasan dan ide.

- Price (harga), yaitu jumlah uang yang harus dibayar oleh pelanggan untuk mempe- roleh produk atau jasa untuk memperoleh satu buah produk dan hendaknya harga akan dapat terjangkau oleh konsumen.

- Place (saluran distribusi/tempat)., termasuk aktivitas perusahaan untuk menyalurkan produk atau jasa tersedia bagi konsumen. Kemudahan akses terhadap jasa bagi para pelanggan. Tempat dimana produk serta merupakan keputusan distribusi menyangkut kemudahan akses terhadap jasa bagi para pelanggan. Tempat dimana produk tersedia dalam sejumlah saluran distribusi dan outlet yang memungkinkan konsumen dapat dengan mudah memperoleh suatu produk.

- Promotion (promosi), berarti aktivitas yang meliputi berbagai metode yaitu iklan, promosi penjualan, mengkomunikasikan produk dan membujuk pelanggan. Menggambarkan berbagai macam cara yang ditempuh perusahaan dalam rangka menjual produk ke konsumen. Penjualan tatap muka dan hubungan masyarakat, mengkomunikasikan produk dan membujuk pelanggan, Menggambarkan berbagai macam cara yang ditempuh perusahaan dalam rangka menjual produk ke konsumen [4].

\section{METODE PENELITIAN}

Penelitian ini dilaksanankan di STIKOM Bali pada Unit Kegiatan mahasiswa yang ada dengan alamat STIKOM Bali, Jl Raya Puputan No.86 Renon Denpasar-Bali. Untuk memperjelas pembuatan dari sistem ini dapat digambarkan dengan Waterfall Methodology [5]. Keseluruhan proses dari pembuatan sistem ini digam-barkan seperti yang terlihat pada gambar berikut :

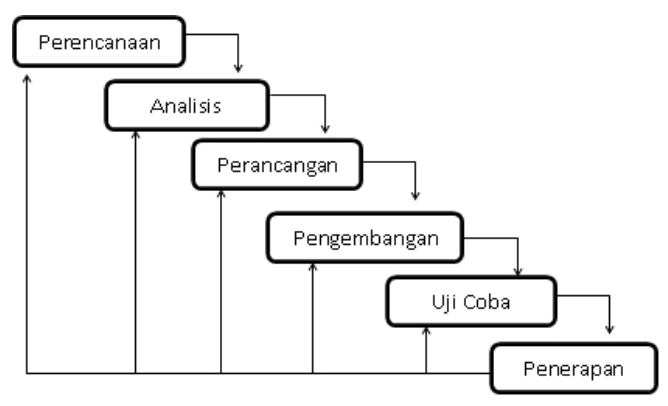

Gambar 1 Metode Penelitian

\section{ROADMAP PENELITIAN}

Roadmap penelitian pada penelitian ini diawali dengan penelitian yang dimulai dengan penelitian pemesanan pakaian pada distro dengan teknologi android pada tahun 20152016. Selanjutnya dilakukan penelian dengan 
implementasi aplikasi penjualan online berbasis Android. Penelitian yang dilakukan saat ini masih menitik beratkan pada platform android, dimana penelitian ini membuat sebuah aplikasi yang nanti dapat dimanfaatkan di lingkungan perguruan tinggi khususnya STIKOM Bali. Aplikasi ini nantinya dapat digunakan untuk melakukan order untuk peminjaman ruangan oleh pengurus UKM. Dari beberapa penelitian yang dilakukan maka arah penelitian selanjutnya melakukan integrasi antara order ke situs e-commerce yang diintegrasikan dengan pengajuan-pengajuan yang dikelola oleh suatu unit di STIKOM Bali. Berikut adalah gambaran dari roadmap penelitian.

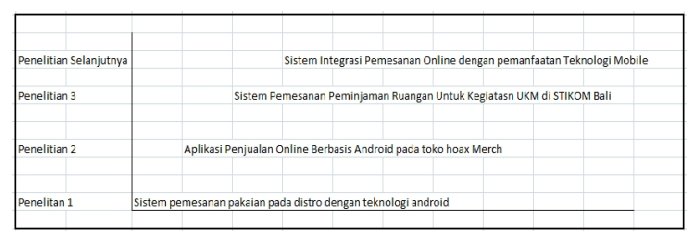

Gambar 2. Roadmap Penelitian

\section{ANALISIS DAN PEMBAHASAN}

Adapun perancangan sistem yang digunakan dalam penelitian ini adalah meng-gunakan UML (Unified Modelling Object), yang tujuannya untuk membuat desain konsep dari sistem yang akan dikembangkan. Di-agramdiagram yang digunakan dalam mela-kukan analisis dan perancangan aplikasi ini adalah : Use case Diagram, Class Diagram, Activity Diagram, Sequence Diagram.

\section{USE CASE DIAGRAM}

Perancangan sistem ini digambarkan dalam 2 buah use case diagram yang tujuannya menjelaskan sebuah konsep da-ri sistem yang dibuat. Use case ini terdiri dai 3 pengguna yaitu

- Kabag Sarpras, menggambarkan oto-risasi yang dapat dilakukan oleh Kabag Sarpras adalah verifikasi user yang me-request agar dapat mengakses sistem ini. Adapun user yang dapat diverifikasi adalah pengurus UKM yang me-request untuk dapat mengakses sistem ini. selain itu Kabag Sarpras juga mempunyai kewenangan untuk mengelola data-data di sistem seperti data pengguna, data mobil, data jadwal pinjaman.
- Staf Sarpras, adalah pengguna yang mempunyai otorisasi untuk melakukan pengelolaan pada sistem hanya sebatas pengelolaan data mobil dan data jadwal. Sehingga dengan adanya pengelolaan data yang dila-kukan dapat di-gunakan oleh pengguna lain-nya dalam mengakses data pada sistem.

- Pengurus UKM, adalah pengguna yang mempunyai otorisasi pada sisem hanya sebatas transaksional saja yaitu transaksi pesan atau booking mobil.

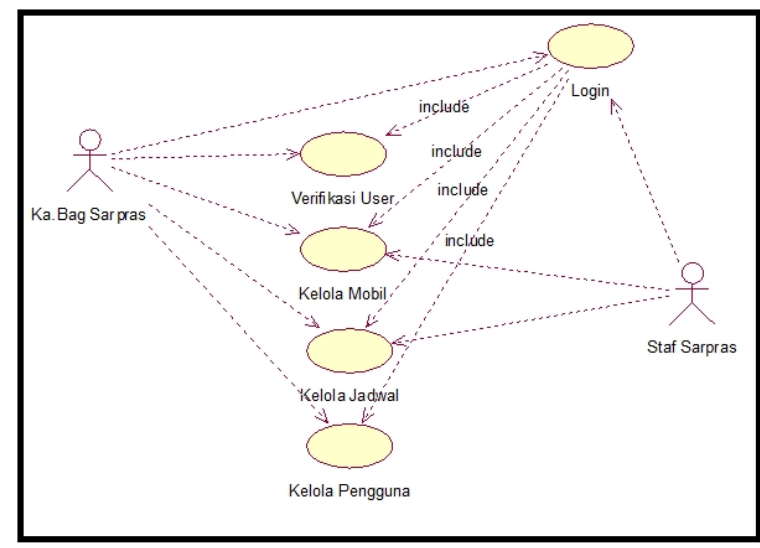

Gambar 3. Use case diagram untuk Kabag Sarpras dan Staf Sarpras

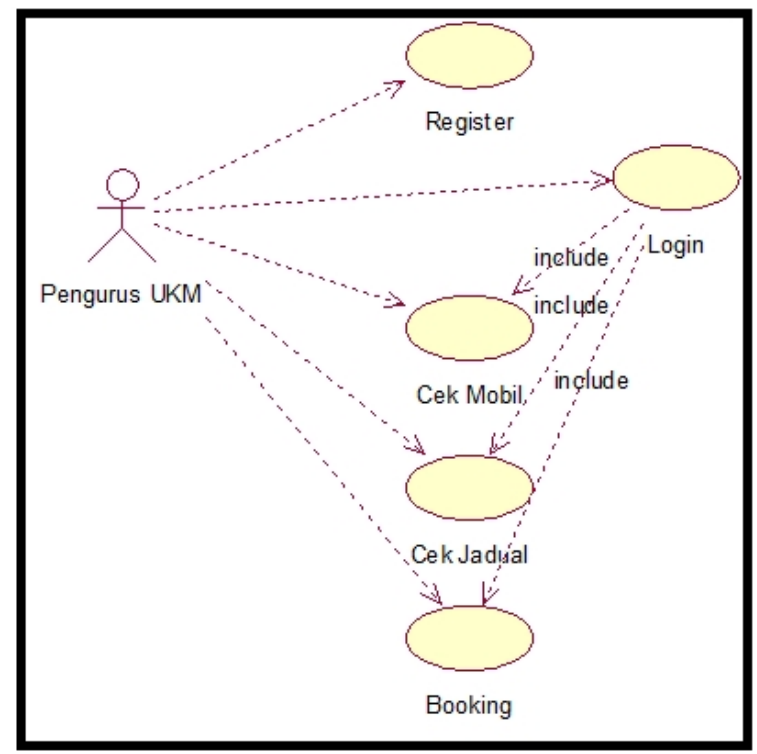

Gambar 4. Use case diagram untuk Pengurus UKM

Pada gambar 3 dan 4 dijelaskan pada sistem yang dibuat ini terdiri dari 3 user, di-mana masing-masing user mempunyai kewe-nangan yang berbeda-beda seperti yang telah dijelaskan. Pada perancangan use case diagram menjelaskan secara umum gambaran dari sistem yang berjalan. 


\section{Class Diagram}

Pada gambar class diagram berikut menggambarkan hubungan antar class pada aplikasi. Class diagram tersebut menggambarkan objekobjek yang terdapat pada class, atribut, dan method yang dapat dilakukan pada saat merancang aplikasi e-booking ruangan.

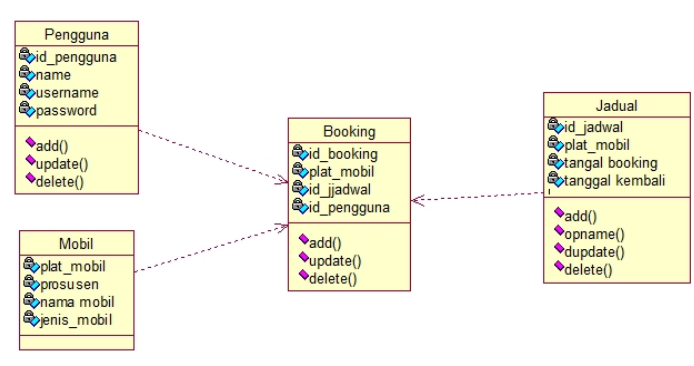

Gambar 4. Class diagram sistem e-booking ruangan

\section{DESAIN INTERFACE}

Sistem yang akan dibuat ini perlu dibuatkan desain dari aplikasi yang akan dibuat nantinya. Berikut ini adalah rancangan umum tampilan aplikasi e-booking ruangan. Dengan dibuatnya desain aplikasi, maka akan semakin memudahkan bagaimana tampilan aplikasi ini akan dibuat. Pada gambar 5 adalah gambaran dari desain interface aplikasi e-booking ruangan

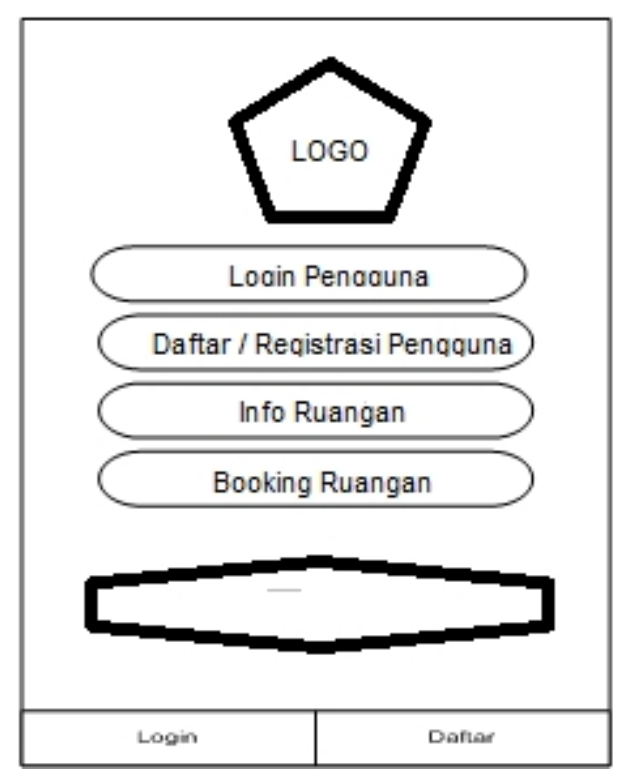

Gambar 5. Desain interface aplikasi e-booking
Dengan dibuatnya rancangan dengan menggunakan pendekatan object oriented ini maka penelitian yang saat ini dilakukan masih berada pada tahap desain dan pengembangan. Untuk selanjutnya penelitian ini akan masuk pada tahap pembuatan program, pengujian, dan implementasi.

\section{SIMPULAN}

Analisis dan perancangan aplikasi e-booking ruangan dengan teknologi mobile. Ini merupakan sebagian dari penelitian yang saat ini masih berjalan dan akan masuk ke tahap pengembangan atau pembuatan program. Beberapa hal yang dapat disimpulkan dari penelitian ini adalah sebagai berikut: Telah dilakukan analisis dan dituangkan da-lam perancangan sebuah aplikasi e-booking ruangan untuk kegiatan UKM di STIKOM Bali, Perancangan yang dilakukan menggunakan pendekatan object oriented dengan meng-gunakan use case dan class diagram, Penelitian ini merupakan bagian dari keseluruhan penelitian yang saat ini baru masuk pada tahap pengembangan atau pembuatan aplikasi.

\section{DAFTAR PUSTAKA}

[1] Madcoms, 2013, Kupas Tuntas Android dengan Pemrograman Android Studio. Andi, Yogyakarta.

[2] Jogiyanto, Hartono, 2010. Analisis, Desain Sistem Informasi dan Web Service. Andi, Yogyakarta.

[3] Adi, Drs Dwi. 2011. Kamus Praktis Bahasa Indonesia. Surabaya: Fajar Mulya.

[4] Barry Render and Jay Heizer, 2011, Prinsip-prinsip Manajemen Operasi, PT.Salemba Emban Patria, Jakarta.

[5] Nugroho, A., (2015), "Rekayasa Perangkat Lunak", Penerbit Informatika, Bandung. 